\title{
The Effect on Stroke Survivors Functional Outcome According to their Gender
}

\section{Abdulmajeed Ali Alkathami ${ }^{1}$, Omar Khaled Ameen ${ }^{2 *}$, Reem Hussein Darwich $^{3}$, Ali Mahmoud Albalawi ${ }^{2}$ and Elhadi Miskeen ${ }^{4}$}

${ }^{1}$ Medical Students, College of Medicine, University of Bisha, Bisha, Saudi Arabia

${ }^{2}$ Stroke Fellow Physician, King Fahad Medical City, Riyadh, KSA

${ }^{3}$ Pediatric Cardiology Fellow Physician, Prince Sultan Cardiac Center, Riyadh, KSA

${ }^{4}$ Department of Obstetrics and Gynaecology, College of Medicine, University of

Bisha, Bisha, Saudi Arabia

*Corresponding Author: Omar Khaled Ameen, Stroke Fellow Physician, King Fahad

Medical City, Riyadh, KSA.
Received: October 25, 2021

Published: November 29, 2021

(C) All rights are reserved by Omar Khaled

Ameen., et al.

\section{Abstract}

Introduction: Functional impairments accumulated after the stroke significantly affect daily living activities, and these patients often need assistance in performing basic life activities. The study aimed to assess the gender differences in functional disabilities among stroke survivors in home care facilities in the Bisha City of Saudi Arabia.

Methodology: An institutional survey was conducted using a standardized proforma. The proforma had the provision for recording sociodemographic details, and post-stroke functional status (degree of disability) was recorded using the Modified Rankin Scale (MRS). Pearson's chi-square test was used to see the association of degrees of disability with various sociodemographic and medical status of the stroke survivors.

Results: The mean mRS score was found to be $3.87 \pm 0.8$, where male stroke survivors showed significantly higher scores ( $4.10 \pm 0.9$ ) compared to females $(3.70 \pm 0.7)(p=0.034)$. The IRS assessment also showed that severe disability was seen in $25.9 \%$ of patients, and it was comparatively higher in male stroke survivors. The degree of disability was also significantly higher among stroke patients who didn't involve in any physical activities ( $p=0.047)$.

Conclusion : Functional status was more severe in male stroke survivors than females. Understanding the gender differences in the health profile would help the health professional for a better orientation of rehabilitative care in order to improve current intervention and/or implement new treatment strategies.

Keywords: Rehabilitation; Stroke; Functional Disability; Health Related Quality of Life

\section{Introduction}

The global prevalence of stroke was estimated to be 101.5 million in 2019, where it was the second leading cause for disabilityadjusted life-years in the geriatric population [1]. Approximately $90 \%$ of stroke survivors have compromised functions, and more than half of the affected individuals need assistance with activities of daily living (ADLs) or instrumental activities of daily living (IADLs) [2,3]. Thus healthcare professionals, including physical therapists, have a pivotal role in reducing the impact of stroke on ADLs. Adequate follow-up and assistance in recovering health and functionality are essential to prevent further disability and also to promote health and functionality. Several factors influence poststroke functional disability such as older age, lesser educational level, the severity of stroke symptoms, depression, anxiety, family support and physical activity or rehabilitative care, and stroke recurrence within 5-years follow-up [4-6]. The stroke rehabilitation clinical guidelines recommend the following: systematic follow-up of patients by a multidisciplinary team, participation of patients in physical exercise programs, and assessment of patients at least once a year to verify the need for new rehabilitation [7]. 
In the Kingdom of Saudi Arabia, the total estimated population size in 2020 was 35.1 million, of which 21.3 million are native Saudis, and 13.6 million are non-Saudis [8]. There is a lack of data regarding the prevalence of stroke and also about the post-stroke functional disabilities experienced by the affected individuals. Even though there is no recent nationwide data regarding the incidence and prevalence of stroke, the rates are low compared to other western countries, as reported by some population-based studies [9$11]$.

Health-Related Quality of Life (HRQoL) is an imperative index for measuring the functional outcomes in stroke survivors. Many factors such as age, gender, social support, disability undertaking, and rehabilitative care are some of the main determinants of HRQoL in these affected individuals [12]. Numerous studies have stated poor functional disabilities among stroke survivors compared to that of the general population $[12,13]$. Although, stroke survivors almost have a less physical disability by the end of the first three to four months and tend to show some gains in functional measures [14]. It is reported that only $25 \%$ of the stroke survivors returned to the level of everyday participation and physical functioning compared to the stroke-free community dwellers [15]. A study done in KSA reported that age and functional abilities play vital roles in influencing HRQoL [16]. The gender differences in numerous aspects of stroke, such as risk factors, clinical features, mortality rate, and functional measures, etc., are well recognized. Female stroke patients who have higher life expectancy than male patients may become a huge burden for society and the healthcare sector [17]. It is thus important to investigate the gender differences in post-stroke functional disabilities among the geriatric population who are stroke victims. There is a scarcity of information related to mortality and functional outcomes in stroke patients in Saudi Arabia. Identifying the health and functional profile of the stroke survivors of a particular region would help assess the common needs of this group. This could be used to implement new and/or modify existing rehabilitative and home care services based on these survivors' identified common needs. Hence this study was aimed to assess the gender differences in post-stroke functional disabilities and associated factors among stroke survivors in the Bisha region of Saudi Arabia.

\section{Methodology}

A cross-sectional study was done among stroke survivors who were residents of elderly home care facilities in Bisha City, Saudi
Arabia. We identified 85 stroke survivors out of 404 home care beneficiaries. The ethical approval to perform the survey was taken from the Research and Ethics Committee of Bisha University. The identified subjects were informed about the purpose and benefits of the study, and consent was taken from all 85 participants.

A standardized proforma was used to collect information that included Sociodemographic characteristics, personal and medical history, information related to rehabilitative (physiotherapy) and home care activities, and a modified Rankin Scale (mRS) [18] was used for assessing functional independence. A single calibrated examiner through a mixture of interview and examination collected information.

\section{Data management and statistical analysis}

The responses obtained were entered in Microsoft Excel and subjected to statistical analysis by an independent biostatistician. An SPSS version 23 (IBM Corp. USA) was used for carrying out the required statistical analysis. Continuous variables were expressed as means with standard deviations, and categorical variables were presented as frequencies and percentages. Association between categorical variables was tested using Pearson's Chi-square test. A probability value ( $\mathrm{p}$-value) less than 0.05 was considered to be statistically significant.

\section{Results}

The mean age of the subject in our study was found to be 79.6 \pm 10.7 years. The sociodemographic characteristics showed that $54.1 \%$ were females, $68.2 \%$ lived in Bisha city, $97.6 \%$ had no formal education, and $65.9 \%$ had a normal Body Mass Index. It was found that $96.5 \%$ were hypertensive, $54.1 \%$ had Diabetes Mellitus, and $14.1 \%$ had Heart diseases. A family history of stroke was reported by $41.2 \%$ of the participants.

The assessment of the Degree of disability or dependence was done using the modified Rankin Scale (mRS). The mean mRS score was found to be $3.87 \pm 0.8$, where male patients showed significantly higher scores $(4.10 \pm 0.9)$ than females $(3.70 \pm 0.7), \mathrm{p}=$ 0.034 . It was found that all the subjects had some form of disability where $25.9 \%$ had a severe disability, $37.6 \%$ had a moderately severe disability, and $34.1 \%$ had a moderate disability (Figure 1). When we evaluated the relationship of Degree of disability with the gender of the participants, it was found the severe disability was comparatively higher in male patients (68.2\%) compared to 
females (31.8\%), whereas moderately severe disability and moderate disability were found to be more in females (56.3\%, 72.4\%) than males, which showed a statistically significant association $(\mathrm{p}=$ 0.013). There was no statistically significant relationship observed with age ( $p=0.971)$ and the Body mass index of the participants ( $p=0.466$ ). Our study found that $45.5 \%$ were doing physical activity during home care, and it was observed that severe disability (54.5\%) was comparatively more in patients who didn't do any physical activity, which showed a statistically significant association ( $p=0.047$ ). Patients' Degree of disability didn't have any significant relationship with the duration spent in-home care $(\mathrm{p}=$ 0.788) (Table 2).

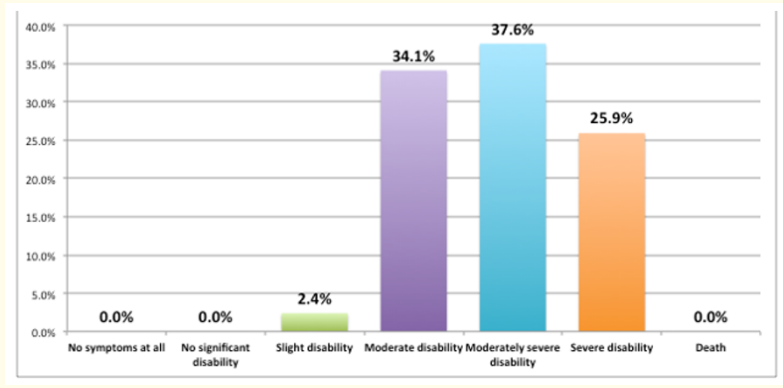

Figure 1: Classification of subjects according to modified ranking scale (mRS).

\begin{tabular}{|c|c|c|c|}
\hline \multirow{2}{*}{ Gender } & Female & Frequency & Percent \\
\cline { 2 - 4 } & Male & 39 & 54.1 \\
\hline \multirow{3}{*}{ Residence } & Bisha city & 58 & 45.9 \\
\cline { 2 - 4 } & Bisha villages & 27 & 68.2 \\
\hline \multirow{3}{*}{ Education } & No formal education & 83 & 97.8 \\
\cline { 2 - 4 } & High school & 1 & 1.2 \\
\cline { 2 - 4 } & University education & 1 & 1.2 \\
\hline \multirow{3}{*}{$\begin{array}{c}\text { Occupation } \\
\text { Body Mass }\end{array}$} & Jobless & 73 & 85.9 \\
\cline { 2 - 4 } index & Retired & 12 & 14.1 \\
\cline { 2 - 4 } & Underweight & 15 & 17.6 \\
\cline { 2 - 4 } & Normal & 56 & 65.9 \\
\hline \multirow{3}{*}{$\begin{array}{c}\text { Smoker } \\
\text { of stroke }\end{array}$} & Obese & 6 & 7.1 \\
\cline { 2 - 4 } & Overweight & 8 & 9.4 \\
\hline \multirow{3}{*}{\begin{tabular}{c} 
Comorbidities \\
\cline { 2 - 4 }
\end{tabular}} & Diabetes Mellitus & 46 & 54.1 \\
\cline { 2 - 4 } & Heart diseases & 12 & 14.1 \\
\hline \multirow{2}{*}{\begin{tabular}{c} 
Family history \\
\cline { 2 - 4 }
\end{tabular}} & No & 50 & 58.8 \\
\hline & Yes & 35 & 41.2 \\
\hline
\end{tabular}

Table 1: Baseline characteristics of the participants.

\begin{tabular}{|c|c|c|c|c|c|c|c|}
\hline \multirow{2}{*}{\multicolumn{2}{|c|}{ Slight disability }} & \multicolumn{4}{|c|}{ Degree of disability or dependence } & \multirow{3}{*}{$\begin{array}{c}\text { Total } \\
46\end{array}$} & \multirow{3}{*}{$\begin{array}{c}\text { P value* } \\
0.013\end{array}$} \\
\hline & & \multirow{3}{*}{ 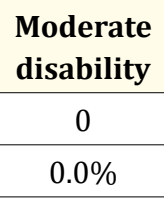 } & \multirow{3}{*}{$\begin{array}{c}\begin{array}{c}\text { Moderately severe } \\
\text { disability }\end{array} \\
21 \\
72.4 \% \\
\end{array}$} & \multirow{3}{*}{$\begin{array}{c}\text { Severe disability } \\
18 \\
56.3 \% \\
\end{array}$} & \multirow{3}{*}{$\begin{array}{c}7 \\
31.8 \%\end{array}$} & & \\
\hline \multirow{4}{*}{ Sex } & \multirow{2}{*}{ Female } & & & & & & \\
\hline & & & & & & $54.1 \%$ & \\
\hline & \multirow{2}{*}{ Male } & 2 & 8 & 14 & 15 & 39 & \\
\hline & & $100.0 \%$ & $27.6 \%$ & $43.8 \%$ & $68.2 \%$ & $45.9 \%$ & \\
\hline \multirow{4}{*}{ Age } & \multirow{2}{*}{$<=65$ years } & 0 & 3 & 3 & 2 & 8 & 0.971 \\
\hline & & $0.0 \%$ & $10.3 \%$ & $9.4 \%$ & $9.1 \%$ & $9.4 \%$ & \\
\hline & \multirow{2}{*}{$>65$ years } & 2 & 26 & 29 & 20 & 77 & \\
\hline & & $100.0 \%$ & $89.7 \%$ & $90.6 \%$ & $90.9 \%$ & $90.6 \%$ & \\
\hline \multirow{8}{*}{$\begin{array}{l}\text { Body Mass } \\
\text { Index }\end{array}$} & \multirow{2}{*}{ Normal } & 2 & 19 & 21 & 14 & 56 & \multirow[t]{8}{*}{0.466} \\
\hline & & $100.0 \%$ & $65.5 \%$ & $65.6 \%$ & $63.6 \%$ & $65.9 \%$ & \\
\hline & \multirow{2}{*}{ Obese } & 0 & 3 & 2 & 1 & 6 & \\
\hline & & $0.0 \%$ & $10.3 \%$ & $6.3 \%$ & $4.5 \%$ & $7.1 \%$ & \\
\hline & \multirow{2}{*}{ Overweight } & 0 & 1 & 2 & 5 & 8 & \\
\hline & & $0.0 \%$ & $3.4 \%$ & $6.3 \%$ & $22.7 \%$ & $9.4 \%$ & \\
\hline & \multirow{2}{*}{ Underweight } & 0 & 6 & 7 & 2 & 15 & \\
\hline & & $0.0 \%$ & $20.7 \%$ & $21.9 \%$ & $9.1 \%$ & $17.6 \%$ & \\
\hline
\end{tabular}




\begin{tabular}{|c|c|c|c|c|c|c|c|}
\hline \multirow{4}{*}{$\begin{array}{l}\text { Physical } \\
\text { activity }\end{array}$} & \multirow{2}{*}{ No } & 0 & 6 & 14 & 12 & 32 & \multirow[t]{4}{*}{0.047} \\
\hline & & $0.0 \%$ & $20.7 \%$ & $43.8 \%$ & $54.5 \%$ & $37.6 \%$ & \\
\hline & \multirow{2}{*}{ Yes } & 2 & 23 & 18 & 10 & 53 & \\
\hline & & $100.0 \%$ & $79.3 \%$ & $56.3 \%$ & $45.5 \%$ & $62.4 \%$ & \\
\hline \multirow{6}{*}{$\begin{array}{l}\text { Duration in } \\
\text { home care }\end{array}$} & \multirow{2}{*}{ 1-2 years } & 1 & 13 & 11 & 11 & 36 & \multirow[t]{6}{*}{0.788} \\
\hline & & $50.0 \%$ & $44.8 \%$ & $34.4 \%$ & $50.0 \%$ & $42.4 \%$ & \\
\hline & \multirow{2}{*}{$2-5$ years } & 1 & 8 & 14 & 7 & 30 & \\
\hline & & $50.0 \%$ & $27.6 \%$ & $43.8 \%$ & $31.8 \%$ & $35.3 \%$ & \\
\hline & \multirow{2}{*}{$>5$ years } & 0 & 8 & 7 & 4 & 19 & \\
\hline & & $0.0 \%$ & $27.6 \%$ & $21.9 \%$ & $18.2 \%$ & $22.4 \%$ & \\
\hline
\end{tabular}

Table 2: Relationship between degree of disability and other baseline characteristics.

${ }^{*} \mathrm{p}$ value $<0.05$ is considered statistically significant.

\section{Discussion}

The current study findings showed that all the stroke survivors in the home care facilities experienced some form of disabilities, with approximately $30 \%$ suffering from severe disability. The literature search shows that there are no long-term follow-up studies done that assessed post-stroke functional disabilities in Saudi Arabia. The male stroke survivors showed comparatively more severe disability than females. A study done by Kim., et al. among Korean stroke survivors reported that females had significantly higher functional disabilities than males [19]. It is suggested that females have worse post-stroke functional outcomes due to many factors such as weaker social and family support, with a majority of them being aged and widowed [20]. Also, females are being frailer and exhibit an imbalance between medical and social factors that make them more vulnerable to functional disabilities [21]. In our study, more than one-third of the stroke survivors didn't attend any physical activities. The social activities of the geriatric population are usually restricted and may have a tendency to receive less physical activity compared to other younger populations.

There are inconsistent findings regarding gender differences in stroke prevalence as some studies showing higher prevalence in aged women [22,23] while some other studies reporting higher prevalence among aged men [24-26]. Many factors influence stroke patients' functioning and/or disability, including body structure and function, participation in physical activity [27]. The environment is found to be a determining factor for the improvement of functional outcomes in stroke patients $[4,28]$. There is a decline in life satisfaction and well-being after stroke in the majority of stroke patients, which is the result of loss of activities [29,30]. Additionally, older people suffering from chronic diseases were found to have a more functional disability and disability in self-care than others free from comorbidities [31]. In our study, the majority of the stroke survivors were suffering from one or more chronic conditions, and these hindered their recovery to normal functional activities. Moreover, these patients often have other impairments of different magnitude, often making it difficult to attend outpatient medical visits independently. Stroke survivors may sometimes find it difficult to reengage in valued post-stroke activities due to money, family, and social support, which are needed to supply personal adapted equipment such as assistive aids, good quality transportation service, and educational support. Thus, it is highly relevant that the rehabilitative activities should focus on constructing a supportive 'post-discharge environment.' Rehabilitative professionals should recognize and eliminate those environmental barriers that pose risks in the improvement of functional disabilities. A family member is usually responsible for caregiving and assisting with healthcare tasks. Thus it is essential to include these family members in the post-stroke follow-up and rehabilitative service planning. Evidence shows that caregivers' involvement in rehabilitative care plans and providing essential education to them could reduce economic burden and increase the care recipients' satisfaction [32].

This survey research has some limitations, and these should be addressed before interpreting the findings. Firstly, this was a single 
institutional study than a multicenter-based or population study, and thus the findings cannot be generalized for all Saudi stroke survivors. Secondly, we didn't collect the pre-stroke mRS scores, and thus it was not possible to evaluate the premorbid functional status and compare it to the post-stroke status. Finally, we couldn't get other information about the stroke patients, such as economic status, caregivers' characteristics, or familial support, all of which might influence the functional outcomes.

\section{Conclusion}

The study findings showed that the severity of disability was comparatively higher among male stroke survivors. The disability was severe in people who didn't involve in any physical or rehabilitative activities. There is a need to identify the factors that influence the severity of functional disabilities, and gender-specific management guidelines should be developed when planning rehabilitative care or physical activities in post-stroke patients.

\section{Bibliography}

1. GBD 2019 Stroke Collaborators. "Global, regional, and national burden of stroke and its risk factors, 1990-2019: a systematic analysis for the Global Burden of Disease Study 2019". Lancet Neurology 20.10 (2021): 795-820.

2. Kim K., et al. "Correlation between the Activities of Daily Living of Stroke Patients in a Community Setting and Their Quality of Life". The Journal of Physical Therapy Science 26.3 (2014): 417-419.

3. Lee PH., et al. "Impacts of stroke and cognitive impairment on activities of daily living in the Taiwan longitudinal study on aging". Scientific Reports 11.1 (2011): 12199.

4. Carvalho-Pinto BP and Faria CD. "Health, function and disability in stroke patients in the community". Brazilian Journal of Physical Therapy 20.4 (2016): 355-366.

5. Lv Y., et al. "Disability Status and Its Influencing Factors Among Stroke Patients in Northeast China: A 3-Year Follow-Up Study". Neuropsychiatric Disease and Treatment 17 (2021): 25672573.

6. Wang YC., et al. "Important factors influencing the return to work after stroke". Work 47.4 (2014): 553-559.

7. Platz T. "Evidence-Based Guidelines and Clinical Pathways in Stroke Rehabilitation-An International Perspective". Frontiers in Neurology 10 (2019): 200.

8. Ministry of Health. Key Health Indicators (2020).
9. Robert AA and Zamzami MM. "Stroke in Saudi Arabia: a review of the recent literature". The Pan African Medical Journal 17 (2014): 14.

10. Al Rajeh S., et al. "Stroke in a Saudi Arabian National Guard community. Analysis of 500 consecutive cases from a population-based hospital". Stroke 24.11 (1993): 1635-1639.

11. Al-Rajeh S., et al. "Stroke register: experience from the eastern province of Saudi Arabia". Cerebrovascular Diseases 8.2 (1998): 86-89.

12. Hackett ML., et al. "Health-related quality of life among longterm survivors of stroke: results from the Auckland Stroke Study, 1991-1992". Stroke 31.2 (2000): 440-447.

13. Suenkeler IH., et al. "Timecourse of health-related quality of life as determined 3, 6 and 12 months after stroke. "Relationship to neurological deficit, disability, and depression". Journal of Neurology 249.9 (2002): 1160-1167.

14. Dobkin BH. "Clinical practice. Rehabilitation after stroke". The New England Journal of Medicine 352.16 (2005): 1677-1684.

15. Lai SM., et al. "Persisting consequences of stroke measured by the Stroke Impact Scale”. Stroke 33.7 (2002): 1840-1844.

16. Gurcay E., et al. "Health-related quality of life in first-ever stroke patients". Annals of Saudi Medicine 29.1 (2009): 36-40.

17. Niewada M., et al. "A International Stroke Trial Collaborative Group. Influence of gender on baseline features and clinical outcomes among 17,370 patients with confirmed ischaemic stroke in the international stroke trial". Neuroepidemiology 24 (2005): 123-128.

18. van Swieten JC., et al. "Interobserver agreement for the assessment of handicap in stroke patients". Stroke 19(1988): 604607.

19. Kim JS., et al. "Gender differences in the functional recovery after acute stroke". Journal of Clinical Neurology 6.4 (2010): 183-188.

20. Kapral MK., et al. "Sex differences in stroke care and outcomes: results from the Registry of the Canadian Stroke Network". Stroke 36 (2005): 809-814.

21. Di Carlo A., et al. "Sex differences in the clinical presentation, resource use, and 3-month outcome of acute stroke in Europe: data from a multicenter multinational hospital-based registry". Stroke 34 (2003): 1114-1119. 
22. Reeves MJ., et al. "Sex differences in stroke: epidemiology, clinical presentation, medical care, and outcomes". The Lancet Neurology 7.10 (2008): 915-926.

23. Haast RA., et al. "Sex differences in stroke". Journal of Cerebral Blood Flow and Metabolism 32.12 (2012): 2100-2107.

24. Wyller TB. "Stroke and gender". The Journal of Gender-Specific Medicine 2.3 (1999): 41-45.

25. Barker-Collo S., et al. "Sex Differences in Stroke Incidence, Prevalence, Mortality and Disability-Adjusted Life Years: Results from the Global Burden of Disease Study 2013". Neuroepidemiology 45.3 (2015): 203-214.

26. Roy-O'Reilly M and McCullough LD. "Age and Sex Are Critical Factors in Ischemic Stroke Pathology". Endocrinology 159.8 (2018): 3120-3131.

27. World Health Organization-WHO. "International Classification of Functioning, Disability and Health-ICF". Geneva. WHO (2001).

28. Rochette A., et al. "Association between personal and environmental factors and the occurrence of handicap situations following a stroke". Disability and Rehabilitation 23.13 (2001): 559-569.

29. Boosman H., et al. "Social activity contributes independently to life satisfaction three years post stroke". Clinical Rehabilitation 25.5 (2011): 460-467.

30. Egan M., et al. "Participation and well-being poststroke: evidence of reciprocal effects". Archives of Physical Medicine and Rehabilitation 95.2 (2014): 262-268.

31. Bayliss EA., et al. "Descriptions of barriers to self-care by persons with comorbid chronic diseases". Annals of Family Medicine 1.1 (2003): 15-21.

32. Gillick MR. "The critical role of caregivers in achieving patientcentered care". JAMA 310.6 (2013): 575-576.

\section{Volume 4 Issue 12 December 2021}

(C) All rights are reserved by Omar Khaled Ameen., et al. 